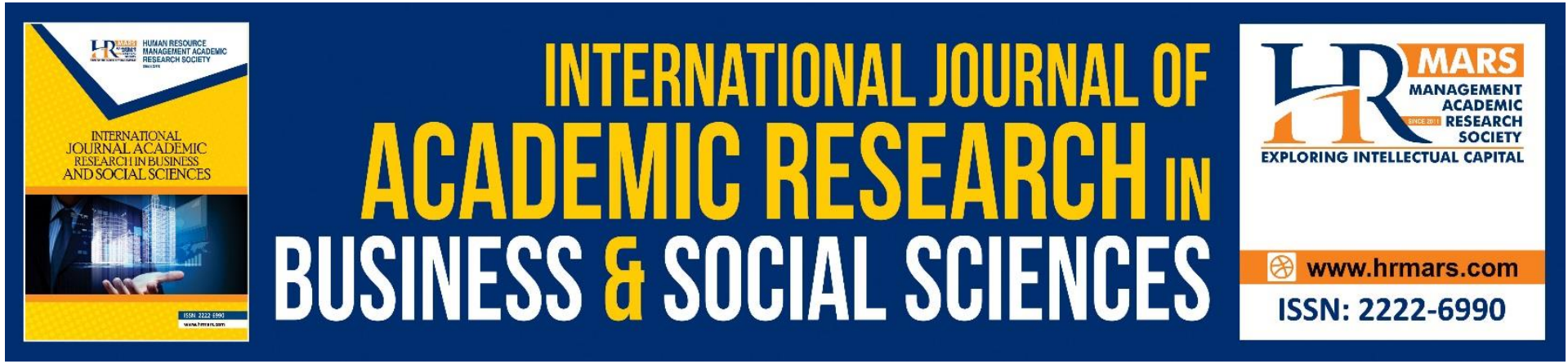

\title{
Occupational Stress and Coping Strategies among Non- tenure Lecturers in a Malaysian Public University
}

Ameiruel Azwan Ab Aziz, Nuramirah Zaini, Sumayyah Shaidin, Ahmad Azfar Abd Hamid

To Link this Article: http://dx.doi.org/10.6007/IJARBSS/v11-i6/10384

DOI:10.6007/IJARBSS/v11-i6/10384

Received: 19 April 2021, Revised: 21 May 2021, Accepted: 02 June 2021

Published Online: 24 July 2021

In-Text Citation: (Aziz et al., 2021)

To Cite this Article: Aziz, A. A. A., Zaini, N., Shaidin, S., \& Hamid, A. A. A. (2021). Occupational Stress and Coping Strategies among Non-tenure Lecturers in a Malaysian Public University. International Journal of Academic Research in Business and Social Sciences, 11(6), 1572-1580.

Copyright: @ 2021 The Author(s)

Published by Human Resource Management Academic Research Society (www.hrmars.com)

This article is published under the Creative Commons Attribution (CC BY 4.0) license. Anyone may reproduce, distribute, translate and create derivative works of this article (for both commercial and non-commercial purposes), subject to full attribution to the original publication and authors. The full terms of this license may be seen at: http://creativecommons.org/licences/by/4.0/legalcode

Vol. 11, No. 6, 2021, Pg. 1572 - 1580

Full Terms \& Conditions of access and use can be found at http://hrmars.com/index.php/pages/detail/publication-ethics 


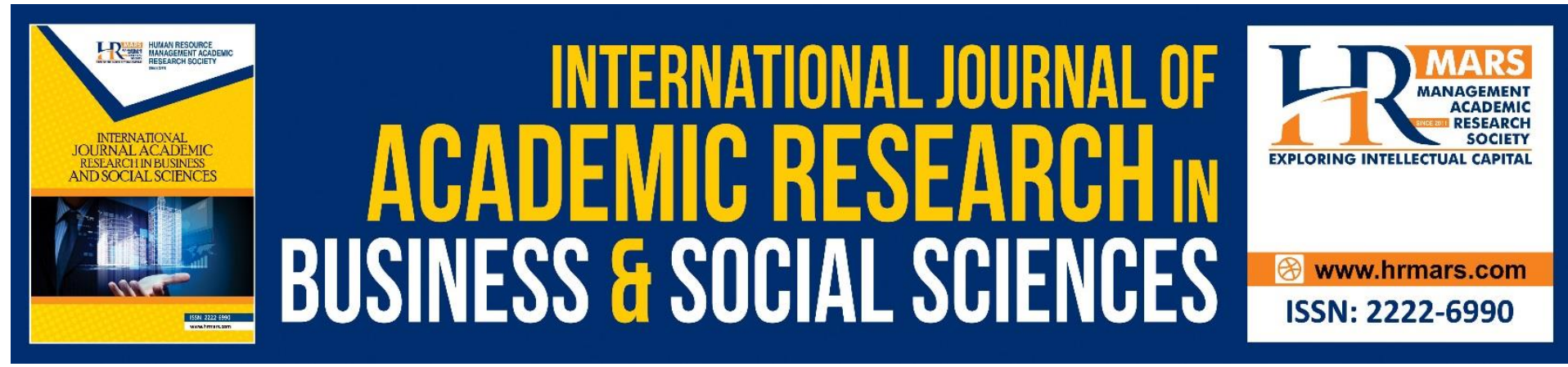

\title{
Occupational Stress and Coping Strategies among Non-tenure Lecturers in a Malaysian Public University
}

\author{
Ameiruel Azwan Ab Aziz, Nuramirah Zaini, Sumayyah Shaidin, \\ Ahmad Azfar Abd Hamid \\ Akademi Pengajian Bahasa, Universiti Teknologi MARA Cawangan Melaka \\ Email: ameirul@uitm.edu.my,nuramirah305@uitm.edu.my, sumayyah@uitm.edu.my, \\ ahmadazfar@uitm.edu.my
}

\begin{abstract}
Of late, the non-tenure lecturers' (NTL) employment is taken to meet the shortage of English language lecturers in Malaysian universities. Significant research has investigated the effects of NTLs' appointments on teaching, students, and university performance; however, little scholarly work has focused on the psychological experiences of NTLs. With the job market's escalating demands, the prevalence of occupational stress has become a matter of great concern for both universities' administrators and NTLs. The purpose of this case study was to shed light and explore NTLs' perceptions of occupational stress sources, stress effects, and coping strategies in a Malaysian public university. Purposive sampling was utilized to recruit study participants who met the sampling criteria. Data gleaned from in-depth semi-structured interviews were analysed using thematic analysis. Results indicate that stigma and novice status was identified as the main stressor, followed by teaching-related engagements, students' negative factors, inadequate infrastructure, and non-teaching related engagements. Personal, social, professional, and institutional coping strategies were the coping strategies used to alleviate stress. The findings suggest prospects for institutional intervention by attending to NTLs' needs to mitigate adverse outcomes for students and universities by providing comprehensive stress training courses.
\end{abstract}

Keywords: Coping Strategies, Non-Tenure Lecturers, Occupational Stress.

\section{Introduction}

Over the past decades, employment under the fixed-term contract has become a trend globally whereby employees were hired for a specified time or until a particular task is completed (Manas et al., 2019). The phenomenon of impermanent employees occurs in many sectors as another option to get cheaper, faster, and less-risked employees (Dwiyanti \& Abdilla, 2018). The phenomenon of contractual term recruitment has also arisen in tertiary institutions where universities and colleges employ contract-based or non-tenure lecturers (NTL) to undertake teaching, research, and administrative duties due to the recurrent shortages of qualified lecturers. In the Malaysian context, it is evidenced that there is an 
increase in the number of NTL recruitments as a measure to meet the shortage challenge by attracting prospective NTL candidates.

There are various explanations for the NTL recruitment trend in higher education. Reduction in higher education expenses, frozen recruitment for permanent posts, competition from private and profit-based institutions, rises in permanent lecture emoluments, and substantial demand for services to cater to various student populations are some of the identified factors to the NTL recruitment trend (Reevy \& Deason, 2014). Although it might not be economically necessary, NTL employment seems to be the right choice for a short-term solution to sustain academic progress. The NTL appointments are commonly dependent on financial allocation and student enrolment on a one-semester basis.

Nevertheless, impermanent employment provides many disadvantages for the NTL who are expected to bear a similar workload as a permanent one but receive inequality in salaries or other facilities (Dwiyanti \& Abdilla, 2018). Moreover, an academic staff appointed on contract term may be given a period within which the employee may be terminated, without appeal, at the discretion of the employing authority (Malaysian Qualifications Agency, 2014). Indeed, NTL recruitment tends to affect an individual in many aspects, such as lack of professional status, ambiguities and confusion, work overload, unfair treatment, low salaries, and job insecurity (Bowen, 2016). This circumstance is severe among educators, but attention to them is still far from satisfying (Situmorang, 2019).

In the educational field, most research addressing the impermanent employment issue revolves around occupational stress in general. Gaining a profound understanding of this issue is critical since occupational stress influences overall work performance. At the time of undertaking the current study, only a few studies have examined the issue from the perspective of NTL in tertiary educational institutions despite the growth in the number of recruitments these days. Given the rising prevalence of this phenomenon, there is an essential need to study NTL stress and its prominent coping strategies to maintain professionalism. It is also highly relevant as the results would indicate how well the NTL can handle occupational demands and gain a better understanding of the factors of their retention in or attrition from the teaching profession. Thus, this study is set out to explore the perspectives of NTL in a Malaysian public university to answer the following research questions:

1. How did the NTL describe their occupational stress and its sources?

2. How did the NTL cope with the stress?

\section{Literature Review}

\section{Occupational Stress, Stress Effect and Coping Strategies}

Many questions have arisen on the impact of NTL in tertiary education, and these questions have been extensively investigated to understand their perspectives on factors affecting their job satisfaction, including work motivation, environment, and organisational commitment (Reevy \& Deason, 2014). The job satisfaction studies have been well-documented in the literature towards a person's performance, particularly on the positive or negative evaluative judgments people make about their jobs (Ingusci et al., 2016). In the educational context, job satisfaction of academic staff in tertiary institutions is crucial in sustaining their motivation and performance, which is very influential in delivering quality education services (Mabaso \& Dlamini, 2017) and the learning process (de Lourdes Machado-Taylor et al., 2016). Empirical evidence suggests that job satisfaction is an essential determinant of occupational success and retention (Skaalvik \& Skaalvik, 2015). Even so, many studies have concluded that ensuring 
job satisfaction is a challenging task due to the presence of pervasive stress in a wide variety of teaching contexts (Bowen, 2016).

Generally, teaching is perceived as a rewarding job, but it also provides a high degree of stress and symptoms of burnout (Skaalvik \& Skaalvik, 2015; Zysberg et al., 2017). Findings from previous studies have shown that this phenomenon occurs globally, such as in the Philippines (Tan, 2017), Saudi Arabia (Mohamed \& Mohamed, 2016), and Nigeria (Aina \& Adeleke, 2018). Bowen (2016) revealed three areas of occupational stress commonly faced by educators: teaching-related stress, workplace relationship-related stress, and organizational-related stress. These stressors are directly affecting them in terms of work overloaded under significant time pressure to be completed.

In the context of this study, stress is termed as an adverse effect resulting from working as an NTL, especially when the occupational demands do not fit the perceived capacity to meet the requirement and lead to negative consequences or unpleasant emotions (Kyriacou, 2001). The experience of stress will show association patterns with burnout (Zysberg et al., 2017). Additionally, stress is also associated with other contextual factors, such as lack of professional recognition (Skaalvik \& Skaalvik, 2015). Reevy and Deason (2014) revealed that even many considered teachings as joyful and provide reasonably high levels of satisfaction, the NTL status is identified as a contributor to their stress.

In higher education institutions, stress involving academic staff primarily due to the responsibilities borne, which are not restricted to the process of teaching and learning but also fulfilling the demand as required in the Key Performance Indicators (KPI) of the universities (Darus, Azizan, \& Ahmad, 2016). Nor Amalina, Huda, and Hejar (2016) reported that occupational stress is experienced by more than two-thirds of academic staff in every university. The pressure derived from the increased work demand (Aina \& Adeleke, 2018) and numerous commitments involving research, publications, consultations, and administrative works (Ismail \& Noor, 2016) which significantly influence their performance and effectiveness in teaching and learning (Adewale, Ghavifekr, \& Abdulsalam, 2017). Indeed, revealing implications of stress is highly noteworthy to sustain the effects on lecturers and the institutions and the students under their supervision (Shaiful Azlan, Rosnah, \& Mohd Rizal, 2017).

Furthermore, the degree of an individual's stress is different, subjected to the intensity, strength, and duration of the stress itself resulted from the pattern of responding or coping with the tension (Aina \& Adeleke, 2018). Hussain, Zulfqar, and Aziz (2019) revealed that academicians profoundly used problem-oriented or emotion-oriented approaches to cope with occupational stress. In addition to the coping strategies involving academic staff, it has also been discovered that physical stress and psychological stress are handled differently (Mohamed \& Mohamed, 2016). The profuse research, which has revealed various strategies in coping with stress, makes it imperative to study a diverse group of people for better understanding, specifically the minority in the educational sector, like NTL, whose contributions could significantly impact the institutions.

Although the literature review on occupational stress issues involving academic staff has been addressed to different degrees, there is still inadequate recent information exclusively on NTL in Malaysian public universities. This issue has not been studied rigorously and thoroughly in the literature because less attention was given to the psychological wellbeing of NTL. Indeed, investigating this specific group that can be considered underprivileged in the institutions would provide great potential to new additional stressors associated with the current practice. 
In an endeavor to fill this lacuna, this study explores perceptions of occupational stress and its consequences among NTL and the identification of common coping strategies used to alleviate the stress effects. Understanding the NTL causes of stress and coping strategies are the primary concern of this study, and therefore may lead to additional insights at higher institutions for further actions.

\section{Methodology}

The present study employed a case study research design to explore NTLs' stress and coping strategies in a Malaysian public university. Case study research design provides a detailed account and analysis of cases and may involve an event, process, object, or person. It also offers chances to identify what complex events or characteristics exist within a specific system. Nieswiadomy (1993) pointed out that a case study is appropriate to be used for engaging in in-depth examinations of people or groups of people or an institution. Utilizing a case study also enables the researchers to explore a given uniqueness to reveal a phenomenon that may not be accessible (Merriam, 2009). Additionally, the case study also enabled the researchers to develop upon existing theories, build new theories, and challenge existing theories. The findings of a case study can facilitate an understanding of the complexities of reality that directly relate to readers' routine and daily experiences.

Qualitative research is interpretive and requires the researcher to recognize biases, personal interests and values, and the methods used to gain entry into the research site (Creswell, 2003); thus, the researchers become the instrument in a qualitative study. On the other hand, Patton (2002) emphasized that information about the researchers should be included in a qualitative report that describes researcher experience and training, personal relationships with the participants and topic studied, and the researchers' perspective. These are essential elements that assist standards of quality and define researchers' role in a qualitative study.

The methods adopted within qualitative research reflect the belief that social phenomena could best be studied through small-scale research to gain a deeper understanding (Silverman, 2000). Purposive sampling was utilized in this study to gain the richest information from those who have experienced the central phenomenon (Patton, 2002). The participants were NTL, who is serving one public university during the data collection period. All participants were recruited based on the list provided by the university administration.

Five female and one male NTL participated in this study. Prospective teachers were solicited during formal and informal meetings and courses and ended when the data reached the saturation level, in which the data gathered was able to answer research questions. The ability to gain additional new information had been accomplished, and further coding was no longer feasible. The search for potential participants ended when the data reached saturation level, in which sufficient information has been obtained to replicate the study, and the data gathered was able to answer research questions. There is no emergent of new data, and the ability to gain additional new information had been accomplished, and further coding was no longer feasible (Glesne \& Peshkin, 1992).

\section{Data Analysis}

In this study, in-depth semi-structured interviews were conducted with each participant. Using the semi-structured interviews, collection of rich and personalised information, personal perspective on outward behaviours of participants (Patton, 2002), and what is in and 
on participants' minds (Merriam, 2001) was able to be obtained. The use of interviews also allows researchers to probe follow-up questions for more clarification of uncertainty to evade misunderstanding and misinterpretation.

All collected data were analysed using analytic and systematic data evaluation using thematic analysis (Ryan \& Bernard, 2000). Thematic analysis is chosen as it focuses more on displaying patterns or themes in the data. It also fits the theoretical orientation of this study in the assumption that gathered data represents the reality of participants' reflections.

The data were analysed inductively in which the themes identified are closely related to the data itself (Patton, 1990). By doing this, it allows the data coding process to expand according to the research questions. The inductive thematic analysis also tends to analyse themes in the data in detail, without giving attention to the related themes from the previous studies. It is aligned with the essentialist method or realist characteristic of thematic analysis in reporting the participants' experiences, the meaning of the experiences, and the effects of the social interactions (Willig, 1999). Data gathered were analysed based on Ryan and Bernard's (2000) six steps of thematic analysis: familiarising with the data, generating initial codes, searching for themes, reviewing themes, defining and naming themes, and producing the report.

Qualitative data analysis is an evolving process involving analytic and systematic data evaluation to seek meanings. To complete the data analysis, strategies to establish quality, substantiate data accuracy, and verification of methods, meanings and interpretations of data were carried out. The data analysis procedures, verification procedures, and procedures to establish quality assist the researcher to decide whether or not the study is credible, dependable, confirmable, and transferable. In this study, member checks (Merriam, 2009) were conducted with the participants to establish the analysis's trustworthiness further. Peer debriefing (Merriam, 2009) was also used in this study to establish the reliability of the analysis by comparing the analysis results among the researchers. Peer debriefing helps clarify interpretations of the data, consider alternative explanations, and defend emergent themes to substantiate results.

\section{Results}

\section{The Sources of NTL Occupational Stress}

The participants in the study acknowledged the presence of stress and encountered accumulation of similar stressors, although they were perceived unconstructively. Participants' descriptions focused on five identified stressors that are considered taxing for them: the stigma of novice status, teaching-related engagements, dealing with students' negative attitude and behaviour, inadequate infrastructure support, and non-teaching related engagements.

The participants expressed their concerns and portrayed that the status of NTL is the major stressor faced. They highlighted to have received frequent negative attitudes and beliefs on their teaching ability, particularly on being young and inexperienced. Several participants added that they experienced more negative treatment because they were not explicitly trained in education. They often felt that the negative attitudes and beliefs toward them have created prejudice, which leads to negative actions and discrimination, particularly when their credibility is questioned and judged.

The second stressor highlighted by the participants is teaching-related engagement. The NTLs in the study revealed that upon their acceptance of the teaching contract, they were briefed on the courses to be taught and no further training afterward. They felt stressed to figure out more information on the courses by themselves. The participants also elucidated 
that they felt redundant tasks often, particularly in teaching similar and overlapping topics across courses and recurring clerical work, contributed to their stress. Impediment in preparing for lessons is another factor mentioned by the participants to add to the stress.

The participants also remarked that dealing with student's negative attitudes and behaviour is a grappling and taxing task. The participants shared their experiences in dealing with students' misbehaviour, lack of motivation, negative perceptions, and passive classroom participation are adding up to their stress. They believed that students hold negative perceptions of them due to their NTL status and received less respect than permanent lecturers. This situation frequently contributes to their stress.

On the other hand, the participants reported that they received inadequate infrastructure support to perform their teaching tasks. They shared that due to their NTL status, they do not have the privilege to use better facilities such as computer laboratories and smart classrooms. They also experienced limited ICT infrastructure and had to rely on their own devices and internet data for their lessons. This stress-producing situation often affects their emotion and work performance.

The last identified stressor shared by the participants is the excessive workload from non-teaching-related engagement. They admitted to having been struggling from the pressure to complete the assigned tasks even though they were not relevant to teaching work. Their experiences encompassed doing numerous clerical work such as keying in data into databases, attending meetings, briefing, and preparing paperwork and documents.

\section{NTLs' Coping Strategies}

In dealing with the occupational stress faced, the participants shared that they would take some time to evaluate the effects of the stress and then look for possible solutions or ways to cope with it. They disclosed that they have used four strategies to assist them in alleviating the stress effects: personal, social, professional, and institutional, where each strategy included two or more specific strategies.

The participants shared that their coping strategies have helped them to deal with the stress. Doing favourite physical activities such as jogging and working out help them to balance their emotion and distracts them from overthinking the stress. Other participants also noted that using cognitive strategies such as compartmentalizing the stress and behavioural strategies like reading books positively impacts them.

Social coping strategies were the second most frequent strategy mentioned by participants in the study. Throughout the interviews, they mentioned how communication with other people helped them persist in their work. They acknowledged that collegial support was desirable and an essential component in coping with the stress. Additionally, they also remarked that turning to family for a simple conversation or reflection is also helpful to deal with the stress.

Professional coping strategies were also remarked as a way to cope with the stress. The participants clarified that to equip themselves to deal with the stress, they need to improve their professionalism. This was done by attending courses on instructional management and improve classroom engagement skills. Searching for teaching strategies on the internet, articles, videos, and pursuing postgraduate studies was also done by the participants to cope with the stress faced. 


\section{Conclusion}

This study shows that the NTLs experienced an accumulation of occupational stress, and the stressors have been identified through their experiences shared through interviews. Furthermore, the results also revealed that the participants appraised the stress and evaluated them before searching for coping methods. Personal, social, professional, and institutional coping strategies were the four strategies utilized by the NTLs either handle and alter the stress or normalize the response to the stress.

This study's results have significantly advanced the understanding of tertiary education by providing insights into the subject and context-specific descriptions of the experiences of the participating NTLs. The knowledge generated from this study could offer recommendations for changes in educational practices in which the authorities and university administrators could collaborate for improvement on NTLs' wellbeing and welfare.

\section{References}

Adewale, A. S., Ghavifekr, S., \& Abdulsalam, I. (2017). Impact of stress on academic staff: Implication for higher education management and leadership. MOJEM: Malaysian Online Journal of Educational Management, 5(2), 75-91.

Aina, S. I., \& Adeleke, O. R. (2018). Job Stress and Coping Strategies among Academic Staff of Faculty of Education in Adekunle Ajasin University Akungba Akoko. International Journal of Innovation and Research in Educational Sciences 5(4), 362-366.

Bowen, A. (2016). Sources of Stress: Perceptions of South African TESOL Teachers. Universal Journal of Educational Research, 4(5), 1205-1213.

Creswell, J. (2003). Research design: Qualitative, quantitative, and mixed methods. Thousand Oaks, CA: Sage Publications, Inc.

Darus, A., Azizan, F. L., \& Ahmad, F. (2016). Work stress, pay satisfaction, psychological empowerment and organisational commitment among academic staff. International Journal of Management Studies (IJMS), 23(1), 51-72.

Dwiyanti, R., \& Abdilla, S. (2018). The effect of job insecurity on organisational commitment in impermanent temporary employees of an Indonesian company. Expert Journal of Business Management 6(1), 40-48.

Ingusci, E., Callea, A., Chirumbolo, A., \& Urbini, F. (2016). Job crafting and job satisfaction in a sample of Italian teachers: the mediating role of Perceived Organisational Support. Electronic Journal of Applied Statistical Analysis, 9(4), 675-687.

Ismail, N. H., \& Noor, A. (2016). Occupational stress and its associated factors among academician in a research university, Malaysia. Malaysian Journal of Public Health Medicine, 16(1), 81-91.

Kyriacou, C. (2001). Teacher stress: Directions for future research. Educational Review 53 (1), 27-35.

Lazarus, R. S., \& Folkman, S. (1984). Stress, appraisal, and coping. Springer publishing company.

Mabaso, C. M., \& Dlamini, B. I. (2017). Impact of compensation and benefits on job satisfaction. Research Journal of Business Management, 11(2), 80-90.

Malaysian Qualifications Agency. (2014). Retrieved from Guidelines to Good Practices: Academic Staff: www.mqa.gov.my

Manas, N. H., Salleh, S., Othaman, S. S., Ridzuan, M. R., \& Abd Rahman, N. A. (2019). A Comparative Study on the Rights and Protection Provided for the Fixed-Term Contract 
Employees between Malaysia and the United Kingdom. Journal of Administrative Science, 16(2), 76-91.

Merriam, S. (2001). Qualitative research and case study applications in education. San Francisco, CA: Jossey-Bass.

Merriam, S. (2009). Qualitative research: A guide to design and implementation. San Francisco, CA.: Jossey-Bass.

Mohamed, A. G., \& Mohamed, L. K. (2016). Occupational Stress and Coping Strategies Among Academicians At Hafr al-Batin University, Saudi Arabia. IOSR Journal of Nursing and Health Science, 5(5), 23-30.

Moustakas, C. (1994). Phenomenological research methods. Thousand Oaks, CA. Sage.

Nieswiadomy, R. M. (1993). Foundations of nursing research. Norwalk, CT: Appleton and Lange.

Nor Amalina, M., Huda, B. Z., \& Hejar, A. R. (2016). Job stress and its determinants among academic staff in a university in Klang Valley, Malaysia. International Journal of Public Health and Clinical Sciences, 3(6), 125-136.

Paronjodi, G. K., Jusoh, A. J., \& Abdullah, M. H. (2017). A comparative study of beginning teacher induction in Malaysia and Victoria (Australia): A review of the literature. Journal of Research, Policy \& Practice of Teachers \& Teacher Education (JRPPTTE), 7(1), 36-48.

Patton, M. Q. (1990). Qualitative Evaluation And Research Methods (2nd ed). Newberry Park: Sage.

Patton, Q. M. (2002). Qualitative research and evaluation methods. London, UK: Sage.

Reevy, G., \& Deason, G. (2014). Predictors of depression, stress, and anxiety among nontenure-track faculty. Front Psychol, 1-17.

Ryan, G. W., \& Bernard, H. R. (2000). Data management and analysis methods. In N. K. Denzin, \& Y. S. (Eds.), Handbook of Qualitative Research (2nd ed) (pp. 769-802). Thousand Oaks, CA: Sage.

Azlan, S. K., Rosnah, I., \& Rizal, M. A. (2017). Systematic review of organisation stressors as predictors for job stress and burnout among university academicians in Malaysia. International Journal of Public Health and Clinical Sciences, 4(3), 35-46.

Silverman, D. (2000). Doing qualitative research: A practical handbook. London, UK: Sage.

Situmorang, B. (2019). Human Resource Management of Contract-Based Teachers and Education Staff to Ensure Quality Education of Senior High Schools in North Sumatera Province. 4th Annual International Seminar on Transformative Education and Educational Leadership (AISTEEL 2019) (pp. 534-538). Atlantis Press.

Skaalvik, E., \& Skaalvik, S. (2015). Job Satisfaction, Stress and Coping Strategies in the Teaching Profession- What Do Teachers Say? International Education Studies 8 (3), 181-192.

Tan, J. S. (2017). Factors affecting stress among faculty members of public universities in the Philippines: A multiple regression analysis. International Journal of Psychological Studies, 9(3), 56-69.

Willig, C. (1999). Beyond appearances: A critical realist approach to social constructionism. In D. J. Nightingale, \& J. Cromby, Social constructionist psychology: A critical analysis of theory and practice (pp. 37-51). Buckingham, UK: Open University.

Zysberg, L., Orenshtein, C., Gimmon, E., \& Robinson, R. (2017). Emotional intelligence, personality, stress, and burnout among educators. International Journal of Stress Management, 24(S1), 122. 